\title{
Perspectives that influence action plans for chronic obstructive pulmonary disease
}

\author{
S Costi BScPT MScEd ${ }^{1,2}$, D Brooks BScPT MSc PhD ${ }^{1,3}$, RS Goldstein FRCPC FRCP(UK) FCCP1,3,4
}

S Costi, D Brooks, RS Goldstein. Perspectives that influence action plans for chronic obstructive pulmonary disease. Can Respir J 2006;13(7):362-368.

BACKGROUND: Prompt treatment of acute exacerbations (AEs) in chronic obstructive pulmonary disease (COPD) improves quality of life and reduces the use of health care resources. Although patient self-management through an individualized action plan (AP) can help with early initiation of therapy, its use is critically dependent on the patient recognizing the features of an exacerbation.

OBJECTIVE: To describe COPD patients' experiences with AEs, as well as health care professionals' (HCPs') attitudes toward the provision of an AP as part of self-management education.

METHODS: Thirty-two patients with moderate to severe COPD who recently experienced at least one AE, and $22 \mathrm{HCPs}$ with experience in the management of COPD, were interviewed.

RESULTS: The most common symptoms and signs associated with an AE were difficulty breathing (84\%), fatigue (81\%), cold symptoms $(59 \%)$, changes in sputum colour $(53 \%)$ or amount $(47 \%)$, and cough (44\%). The main precipitants identified were environmental triggers (47\%), infective agents (31\%), excessive activities (25\%), emotional factors $(16 \%)$ and changes in medications $(9 \%)$. Strategies for dyspnea relief included increasing medications $(72 \%)$, resting $(56 \%)$, avoiding exposure to environmental triggers (41\%) and performing breathing exercises $(31 \%)$. Patients supported the use of an AP and recommended that it be individualized for symptoms and triggers, and that it should also include strategies for addressing anxiety and depression. HCPs also supported the use of an individualized AP and recommended that it be regularly revisited, depending on the patient's disease severity.

CONCLUSIONS: Patients' experiences with AEs do not always conform to a standard medical definition. Therefore, an understanding of their experience is of value in the design of an individualized AP. HCPs support the use of an AP that emphasizes self-management of exacerbations as well as general COPD management.

Key Words: Action plan; COPD; Exacerbation; Self-management
Facteurs qui influent sur les plans d'action dans la maladie pulmonaire obstructive chronique

HISTORIQUE : Le traitement rapide des poussées d'exacerbation (PE) dans la maladie pulmonaire obstructive chronique (MPOC) améliore la qualité de vie et réduit le recours aux services de santé. La prise en charge de sa maladie par le patient grâce à un plan d'action individualisé peut faciliter l'instauration rapide du traitement des PE, mais son application dépend très étroitement de la capacité du patient à reconnaître les signes de l'exacerbation.

OBJECTIF : Décrire l'expérience des patients atteints de MPOC qui présentent des $\mathrm{PE}$ et la position des professionnels de la santé vis-à-vis de la remise d'un plan d'action à leurs patients dans le cadre de l'enseignement de l'autotraitement.

MÉTHODES : Les chercheurs ont interrogé trente-deux patients atteints de MPOC modérée à sévère qui ont récemment présenté au moins une PE et 22 professionnels de la santé qui connaissent bien le traitement de la MPOC.

RÉSULTATS : Les signes et symptômes les plus courants de la PE ont été : la gêne respiratoire ( $84 \%$ ), la fatigue ( $81 \%)$, les symptômes du rhume (59\%), les changements de couleur (53\%) ou de volume (47\%) des expectorations et la toux $(44 \%)$. Les principaux facteurs déclencheurs identifiés ont été liés à l'environnement (47\%), à des agents infectieux (31\%), à des activités excessives (25\%), au stress émotionnel (16\%) et à des changements pharmacologiques $(9 \%)$. Les stratégies visant à soulager la dyspnée ont inclus : l'augmentation des posologies (72\%), le repos (56\%), l'évitement des déclencheurs environnementaux (41\%) et les exercices respiratoires (31\%). Les patients ont été en faveur du plan d'action; ils ont recommandé son individualisation en fonction des symptômes et des déclencheurs et ont suggéré qu'on y ajoute des stratégies pour faire face à l'anxiété et à la dépression. Les professionnels de la santé ont aussi appuyé le recours au plan d'action individualisé et ont préconisé sa mise à jour périodique, selon la gravité de la maladie des patients.

CONCLUSIONS : L'expérience des patients qui manifestent des PE ne concorde pas toujours avec la définition médicale standard. C'est pourquoi, au moment d'élaborer un plan d'action, il est utile de comprendre concrètement leur situation. Les professionnels de la santé appuient le recours à un plan d'action qui aide les patients à mieux prendre en charge leurs exacerbations et leur MPOC en général.
Qtrategies that promote disease self-management often $\checkmark$ include the provision of an action plan (AP), which enables patients to adjust their treatment in response to changes in the severity of their condition (1-7). For example, a review of 32 studies (8) found that self-management education for asthma was associated with improvements in airflow, self-efficacy, the number of school days missed, activity restriction and emergency room visits. However, randomized controlled trials examining self-management in chronic obstructive pulmonary disease (COPD) report conflicting results (9-12), and one such trial that evaluated the role of APs in COPD (12) noted changes in the pattern of use of medications, but no differences in healthrelated quality of life between those who had an AP and those who did not. Because exacerbations are the single most important driver of health care utilization in COPD, there is increasing interest in any approaches that may reduce their frequency

${ }^{1}$ West Park Healthcare Centre, Toronto, Ontario; ${ }^{2}$ University of Modena and Reggio Emilia, Modena, Italy; ${ }^{3}$ Department of Physical Therapy;

${ }^{4}$ Department of Medicine, University of Toronto, Toronto, Ontario

Correspondence: Dr Roger S Goldstein, West Park Healthcare Centre, 82 Buttonwood Avenue, Toronto, Ontario M6M 2J5.

Telephone 416-243-3631, fax 416-243-8947, e-mail rgoldstein@westpark.org 


\section{TABLE 1}

Questions asked of patients with chronic obstructive pulmonary disease

"I would like you to picture your last flare-up or serious breathing episode. Please tell me everything that you can remember leading up to this flare-up"

1. Symptoms before an exacerbation:

a) How did your last flare-up start?

b) Which words would you use to describe any indications or feelings that usually precede your flare-ups?

c) Can you describe the difference between a 'normal day' and a day preceding a flare-up?

2. Trigger factors for breathing difficulties:

a) Have you noticed anything that may trigger (bring on) breathing difficulties?

3. Relieving factors:

a) What do you do to lessen your breathing discomfort?

4. Medical management of an acute exacerbation:

a) Did you go to the hospital emergency room or make an unscheduled visit to your family doctor, or did you treat your serious episode at home?

5. Patient feedback on examples of action plans:

a) Here are some examples of action plans used in asthma or chronic obstructive pulmonary disease. What do you think of them?

b) Some action plans include a daily diary; do you think you would be able to complete one?

c) If you had an action plan, do you think it would help you deal with a flare-up?

or severity $(13,14)$. As Wilkinson et al $(13)$ showed in a study of 128 patients who experienced 1099 exacerbations, patient recognition of exacerbation symptoms and prompt treatment improved exacerbation recovery, reduced the risks of hospitalization and was associated with a better health-related quality of life. Although there have been no studies on COPD that have evaluated the influence of an AP alone on the timing of exacerbation management, written guidelines on the management of COPD exacerbations support their use $(15,16)$. Given that the application of an AP depends on the patient recognizing the presence of an exacerbation, patients may be slow to initiate the AP unless it includes the symptoms and signs of an acute exacerbation (AE) with which they are familiar (17). However, many APs are not individualized but are instead based solely on medical definitions used in clinical trials. Another barrier to the use of APs occurs if experienced health care professionals (HCPs) do not strongly support their use as an effective clinical tool.

In the present article, we report the results of interviews with COPD patients and HCPs, regarding their experiences with AEs and their attitude toward the usefulness of APs as a clinical tool, respectively. These observations will assist in the development and application of individualized APs for patients with COPD.

\section{METHODS}

The study received approval from West Park Healthcare Centre's Research Ethics Committee. All HCPs and individuals with COPD gave written, informed consent. Structured interviews were used to collect qualitative data, which were analyzed using content analysis (18). This descriptive design was used because little is known about

\section{TABLE 2}

Questions asked of health care professionals

1. Objectives of an action plan:

a) What do you think should be the objectives of an action plan?

b) Do you think an action plan should focus only on the management of an acute exacerbation or do you think that it should also be directed toward the general management of chronic obstructive pulmonary disease?

2. Warning signs and symptoms of an acute exacerbation:

a) What do you think are the signs and symptoms best recognized by patients which can be easily linked to a modification of health status?

3. Action plan revision frequency:

a) How often do you think an action plan should be revisited?

4. Patient education on the effective use of an action plan:

a) What is the best way to teach patients the effective use of an action plan?

5. Health care professional feedback on the action plan examples:

a) Here are some examples of action plans used in asthma and chronic obstructive pulmonary disease. What do you think of them?

the attitudes and perceptions toward APs, either among individuals with COPD or among HCPs. The same investigator, not involved in the clinical care of the patients, interviewed all patients and HCPs using a standardized approach from a written script. The study was conducted in a chest clinic associated with a rehabilitation centre that specializes in chronic disease management.

\section{Protocol}

COPD patients and HCPs were interviewed using two different structured questionnaires with open-ended questions (Tables 1 and 2); the questionnaires were developed following a comprehensive literature review. Clinical investigators who specialized in the areas of asthma and COPD management were contacted, and copies of their APs were requested. Questionnaires were developed by the research team, pretested for clarity in pilot interviews and modified based on the received feedback. Purposive sampling was used by selecting participants who could best inform the research question. Notes taken during the interviews were used for data analysis. Patients described their experience of their most recent 'flare-up', providing information concerning symptoms, triggers and relieving factors. HCPs were asked their opinion regarding the application of an AP for patients with COPD and the best way for the HCP to present it to the patient. Patients and HCPs were then asked to comment on two COPD-specific APs $(6,19)$ and two asthma-specific APs $(20,21)$. They were asked whether daily diary completion would be feasible. Interviews occurred in a quiet location at the health care centre. Interviews were recorded and transcribed verbatim within $48 \mathrm{~h}$.

\section{Patients with COPD}

Information was collected from patients who had completed a comprehensive pulmonary rehabilitation program, including patient education over the past year, and who were attending a follow-up clinic or respiratory support group, as well as patients not previously enrolled in an educational or a rehabilitation program, who were newly referred for this purpose. It was examined whether these two groups of patients had different perspectives.

Enrollment criteria included a diagnosis of COPD (22) for at least five years, with moderate to severe airflow limitation, at least one $\mathrm{AE}$ over the past six months (diagnosed by an $\mathrm{HCP}$ ) and the 
TABLE 3

Characteristics of chronic obstructive pulmonary disease (COPD) patients

\begin{tabular}{lccc}
\hline & $\begin{array}{c}\text { Postrehabilitation } \\
\text { patients } \\
\text { (n=20) }\end{array}$ & $\begin{array}{c}\text { New } \\
\text { patients } \\
(\mathbf{n = 1 2})\end{array}$ & $\begin{array}{c}\text { Total } \\
(\mathbf{n = 3 2})\end{array}$ \\
\hline Age, mean years $\pm \mathrm{SD}$ & $69 \pm 7$ & $65 \pm 7$ & $68 \pm 8$ \\
Sex, $\mathrm{n}(\%)$ & & & \\
$\quad$ Male & $11(55)$ & $7(58)$ & $18(56)$ \\
$\quad$ Female & $9(45)$ & $5(42)$ & $14(44)$ \\
FEV ${ }_{1}$, mean \% predicted $\pm \mathrm{SD}$ & $38 \pm 13$ & $30 \pm 9$ & $35 \pm 12$ \\
COPD severity of airflow, $\mathrm{n}(\%)^{*}$ & & & \\
$\quad$ Stage IV & $6(30)$ & $6(50)$ & $12(38)$ \\
$\quad$ Stage III & $11(55)$ & $6(50)$ & $17(53)$ \\
$\quad$ Stage II & $3(15)$ & - & $3(9)$ \\
Frequent exacerbators, $\mathrm{n}(\%)^{\dagger}$ & $11(55)$ & $5(42)$ & $16(50)$ \\
Time since last AE, mean weeks $\pm \mathrm{SD}$ & $9 \pm 8$ & $12 \pm 9$ & $10 \pm 8$ \\
$\mathrm{O}_{2}$ therapy, $\mathrm{n}(\%)$ & $4(20)$ & $2(17)$ & $6(19)$ \\
English as a second language, $\mathrm{n}(\%)$ & $3(15)$ & $1(8)$ & $4(12)$ \\
\hline
\end{tabular}

${ }^{*}$ As defined by the Global Initiative for Chronic Obstructive Lung Disease (GOLD) (21); ${ }^{\dagger}$ As defined by Seemungal et al (23). AE Acute exacerbation; FEV $V_{1}$ Forced expiratory volume in $1 \mathrm{~s}$

ability to provide informed consent. Individuals were excluded if they had associated comorbidities that limited their compliance or if they were unable to communicate for the purpose of the study.

\section{HCPs}

HCPs were approached if they had at least three years of experience in the acute care of patients with respiratory disease or management of COPD, as a nurse, respiratory therapist, physiotherapist, occupational therapist, clinical psychologist, dietitian, general practitioner or respiratory specialist. These criteria were arbitrarily chosen by the research team.

\section{Data analysis}

Data analysis was conducted after completion of data collection. Notes from the interviews were used for content analysis. From the responses, the results were presented in terms of response frequency (mean $\pm \mathrm{SD}$ ). One investigator (SC) manually extracted the main points from each responder, which were then confirmed independently by a second investigator (DB). Responses were grouped under common headings; for example, the term 'shortness of breath' included the responses "breathing in was $\mathrm{OK}$ but the breathing out was terrible", "I was short of breath even at rest" and "I was out of breath".

\section{Patients' perspective}

\section{RESULTS}

Interviews were conducted with 32 patients with COPD, of whom 20 had completed pulmonary rehabilitation and 12 had been recently referred. The demographic and clinical characteristics of those interviewed are summarized in Table 3. Although education was provided as part of the rehabilitation program, none of the patients had been provided with a written AP. Sixteen of the patients (50\%) had frequent exacerbations (ie, three to eight episodes per year) as defined by Seemungal et al (23). For the entire sample, the mean time since the most recent exacerbation was $10 \pm 8$ weeks. Ten patients (31\%) were admitted to hospital following an unscheduled visit to their family doctor (four patients) or the

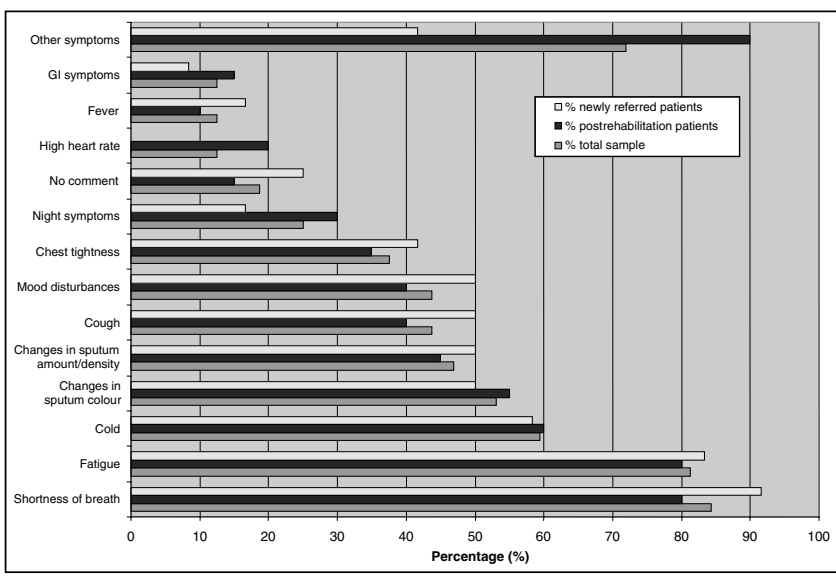

Figure 1) Perspectives of chronic obstructive pulmonary disease patients regarding the symptoms associated with the onset of an acute exacerbation. The $x$-axis shows the percentage of patients who identified a given symptom as a leading factor and the y-axis shows the different symptoms identified. Mood disturbances included anxiety, panic, depression and stress. Night symptoms included cough, poor sleep and the inability to lie flat. GI Gastrointestinal

emergency room (six patients). Ten patients (31\%) returned home after an unscheduled visit to their family physician and five patients (16\%) returned home after an unscheduled visit to the emergency room. Seven patients (22\%) were able to selfmanage their acute episode because they had been provided with appropriate medications (steroids and antibiotics) and were encouraged to initiate them on recognizing an exacerbation.

Symptoms associated with the onset of an AE: Symptoms associated with an exacerbation are summarized in Figure 1. Difficulty breathing and fatigue, which included an inability to cope with usual activities, were the most commonly reported symptoms ( $84 \%$ and $81 \%$, respectively), followed by symptoms of a cold or flu $(59 \%)$, changes in sputum colour $(53 \%)$, sputum volume or density (47\%) and the presence of an increased cough (44\%). Mood disturbances, including anxiety, panic, stress or depression, were frequently noted (44\%). Symptoms mentioned by fewer than three individuals were not categorized.

Trigger factors for an AE: Trigger factors are summarized in Figure 2. These included the following: environmental triggers $(47 \%)$, such as the weather, dust, pollutants and odours; infective agents $(31 \%)$, such as a cold or sore throat; excessive activities (25\%), including lack of sleep; emotional factors $(16 \%)$, such as anxiety, stress and being upset; and changes in medications $(9 \%)$. Nine patients $(28 \%)$ were unable to name any factor that may have contributed to their last exacerbation. Relieving factors: Several strategies were used to relieve breathing discomfort (Figure 3). These included medications (72\%) (prescribed, over-the-counter and oxygen) and rest (56\%), including reduced activity levels, slower activities, more sleep, deliberate relaxation and energy conservation. Other strategies included avoidance of exposure to triggers (41\%) (eg, environmental factors, emotional factors and infective agents), breathing exercises (31\%) and general exercise (9\%). Relieving factors mentioned by fewer than three individuals, such as eating carefully, using walking aids and sleeping with more pillows, were not categorized.

Patient feedback on examples of an AP: Twenty-two patients (69\%) provided feedback on the four APs, recommending that they be clear, simple and individualized for triggers, early 


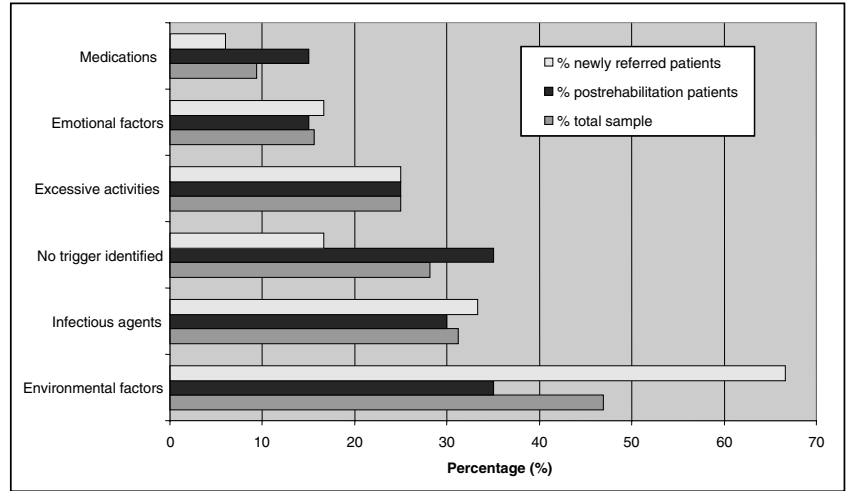

Figure 2) Perspectives of chronic obstructive pulmonary disease patients regarding the main triggers of an acute exacerbation. The $x$-axis shows the percentage of patients who identified a given factor as a trigger and the $y$-axis shows the different triggers identified. Environmental factors included weather, dust, pollutants and odours. Excessive activities included increased effort, overdoing activities, exercise, and lack of sleep or rest. Medications included recent use of antibiotics and changes to usual medications

symptoms and the timing of actions to be taken. They also stated that APs should include baseline pulmonary function and any tools that would help for controlling anxiety and depression. They recommended against lengthy APs and small fonts, with many suggesting that the length should not exceed one to two pages, so that the AP could be kept in a visible place in the house, or together with medications.

Forty-four per cent of patients were prepared to complete a daily diary and $22 \%$ were already doing so. Thirty-seven per cent were not prepared to keep a daily diary and $19 \%$ could not comment. When asked whether they thought that an AP would assist them in dealing with a flare-up, 50\% reported that it would, $31 \%$ were uncertain and 19\% stated that it would not. Reasons for the absence of effectiveness of an AP included: 'already following the indications of the AP', 'lack of compliance with recommendations of HCPs' and 'flare-ups happening unpredictably'.

\section{Perspectives of the HCPs}

Interviews were conducted with $22 \mathrm{HCPs}$ who were experienced in the management of COPD: physiotherapists $(n=7)$, respiratory therapists $(n=4)$, registered nurses $(n=3)$, occupational therapists $(\mathrm{n}=2)$, respiratory specialists $(\mathrm{n}=2)$, general practitioners $(\mathrm{n}=2)$, a dietician $(\mathrm{n}=1)$ and a clinical psychologist $(\mathrm{n}=1)$.

Objectives of a COPD-specific AP: The main objectives when using a COPD-specific AP are summarized in Figure 4, the most common being patient self-management $(73 \%)$, patient recognition of an $\mathrm{AE}(64 \%)$ and day-to-day management of COPD (36\%). The majority of respondents (77\%) recommended that the AP address general COPD management as well as management of an $\mathrm{AE}$.

Signs and symptoms recognized by COPD patients: HCPs stated that patients could recognize symptoms and signs of an AE consistent with the Anthonisen criteria $(23,24)$, namely, increased dyspnea, increased sputum volume or purulence, plus minor signs, such as upper respiratory tract infection, fever, increased wheezing, coughing, increased respiratory rate and increased heart rate (Figure 5). Many HCPs (68\%) suggested that the warning symptoms should be individualized as patient experiences varied. Fifty-five per cent of respondents identified fatigue as an important warning sign and some identified

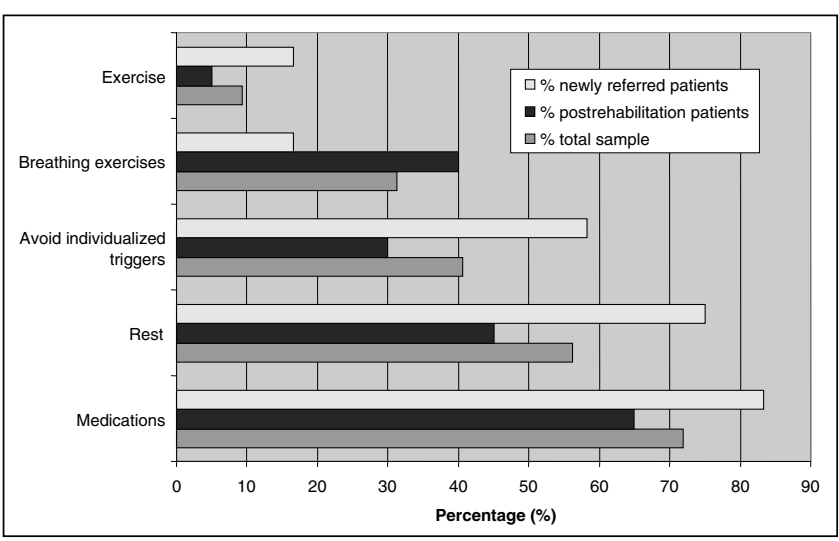

Figure 3) Perspectives of chronic obstructive pulmonary disease patients on relieving factors during an acute exacerbation. The $x$-axis shows the percentage of patients identifying a relieving factor and the $y$-axis shows the various factors identified. Medications include oxygen therapy and over-the-counter medications. Rest includes a reduced activity level, slower activities, more sleep, active relaxation and energy conservation. Individualized triggers include environmental factors, emotional factors and potentially infectious agents

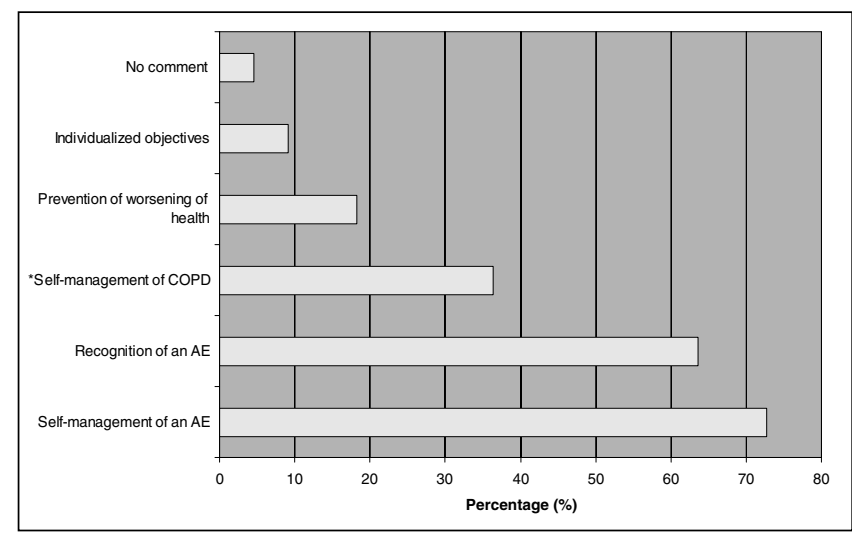

Figure 4) Initial response of health care professionals regarding the objectives of a chronic obstructive pulmonary disease (COPD) action plan. The $x$-axis shows the percentage of health care professionals who identified a given objective and the $y$-axis shows the various objectives. Self-management of acute exacerbations (AEs) includes options for treatment, timing for medications and medical attention. AE recognition includes the definition of an $A E$ and its identification from warning symptoms and signs, and monitoring for signs of infection. *Day-to-day self-management of COPD includes monitoring of baseline conditions, education regarding lifestyle activities and strategies to maintain overall health. Prevention of worsening health includes education about individualized trigger factors, prevention of AEs, hospital admissions and physician visits. Individualized objectives include specific issues such as nutritional issues and relaxation

chest tightness and nocturnal symptoms as important. Signs and symptoms reported by fewer than three individuals, such as dizziness, swollen ankles and mood disturbances, were grouped under the category of 'other symptoms'.

Revisiting the AP: Most HCPs (68\%) thought the AP should be revisited regularly according to disease severity, with many (50\%) suggesting that the AP should be reviewed after each exacerbation, especially if there had been any changes in the medication regimen $(23 \%)$. HCPs recommended that the AP should be reviewed more frequently until the patient reached a good understanding of how to integrate it into a daily routine. 


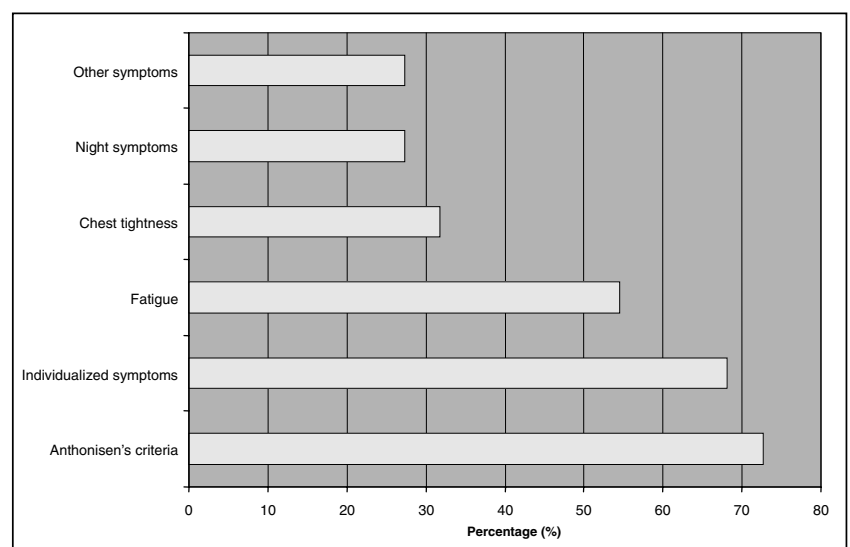

Figure 5) Perspectives of health care professionals on the symptoms of an acute exacerbation most recognizable by chronic obstructive pulmonary disease patients. The $x$-axis shows the percentage of health care professionals who identified a given symptom associated with an acute exacerbation as recognizable by chronic obstructive pulmonary disease patients. The y-axis shows the different symptoms identified. Anthonisen's criteria includes the major (dyspnea, or sputum volume or colour change) and minor criteria (24). Individualized symptoms included changes from a patient's baseline. Fatigue included inability to cope with usual activities, feeling poorly, feeling weak and having low energy. Night symptoms included cough, poor sleep and inability to lie flat

Patient education on the effective use of the AP: Individual sessions $(73 \%)$ and small group sessions (55\%) were the most commonly advocated forms of patient education. Other suggestions included an extended course of education, which would enable repetition and integration into a patient's routine $(45 \%)$. Patient-centred learning techniques that encompassed their personal experience of the disease, with the inclusion of the caregiver and the family physician, were also recommended.

HCP feedback on examples of an AP: Most HCPs (68\%) recommended that the AP be short - preferably condensing the information into a clear, simple, one-to-two page tool. It was suggested that the content should be patient-specific, including baseline measurements and medication lists. The credit card format, often used in asthma APs, was not thought to be sufficient and many drew attention to the possibility that COPD patients would have difficulty reading small fonts. Many HCPs (45\%) thought that COPD patients would be unlikely to complete a daily diary over an extended period of time.

\section{DISCUSSION}

Although several reports support self-management education for patients with asthma (25), when the same asthma educational program was delivered to patients with COPD, responsiveness was substantially less than that seen among the asthma patients (26), confirming that these two conditions require different educational content. Professional societies in several North American $(15,21,27,28)$, European (29) and Asian countries (30) recognize the importance of COPD patient education for improving skills, ability to cope and health status. Although patient education includes associated secondary impairments, generalized deconditioning and psychological stressors $(31,32)$, there is limited experience in using APs to guide self-management of an AE (33). Given that even in clinical studies many patients delay reporting an $\mathrm{AE}$ to their clinical team (14), approaches that may provide prompt exacerbation self-management are of value (34).

The issue of an AP being individualized to include the patient's experience of an exacerbation was overwhelmingly endorsed by both patients and HCPs. Although most patients included one or more of the major Anthonisen criteria (24) (increased dyspnea, increased sputum amount or a change in sputum colour) in their description of an $\mathrm{AE}$, many recognized that fatigue, cold symptoms and mood disturbances also occur frequently. In fact, the symptom of fatigue, which is not part of any current standard definition of an $\mathrm{AE}$, was experienced by $81 \%$ of patients (second only to dyspnea at $84 \%$ ), and mood disturbances were reported by $44 \%$. Fatigue was noted as a key symptom by more than one-half of HCPs, who also noted the wide variety of symptoms experienced by patients. While we are not suggesting that an $\mathrm{AE}$ be defined only by the presence of fatigue or a mood change, it is important to note that these nonrespiratory symptoms frequently accompany an $\mathrm{AE}$, and should be included in the list of symptoms that patients are taught to associate with an AE. The HCPs emphasized the importance of revisiting the AP periodically, especially following an $\mathrm{AE}$, which is not a common practice to our knowledge.

Some patients $(19 \%)$ did not report recognition of any leading symptoms associated with an $\mathrm{AE}$ and $28 \%$ could not identify any trigger factors. This group of 'poor perceivers' may be the ones least likely to use an AP effectively. Douglass et al (17) noted that six of 62 patients who did not use their asthma AP included three 'poor perceivers' who lacked body awareness and confidence in identifying an asthma attack at onset and, hence, in determining when to start using the AP. Of note, in the Douglass study (17), 14 of 23 patients who did use an AP, modified it according to their own experience, and 15 of 22 patients who did not have an AP indicated that it had not been provided to them by an HCP.

Patients reported a variety of $\mathrm{AE}$ triggers and strategies for alleviating symptoms. Therefore, patient-specific environmental and emotional factors, as well as excessive activities and medication changes, should be included if the AP is to be individualized. Accumulating evidence on the effectiveness of an AP is challenging, because it is difficult to use double-blind methodology in such trials with respect to the interventions tested, and comparisons among different medical centres is made difficult because the content and mode of teaching may differ. However, in a study by Watson et al (12), 34\% of the intervention group and $7 \%$ of the control group $(\mathrm{P}=0.04)$ initiated prednisone therapy and $44 \%$ versus $7 \%$, respectively, initiated antibiotics in response to worsening symptoms $(\mathrm{P}=0.02)$.

Most HCPs recommended a COPD-specific AP, targeted to the management of AEs as well as to the general management of the condition. The former should include warning signs and symptom recognition, together with time-related actions. The latter should include strategies for the prevention of an $\mathrm{AE}$, monitoring of baseline signs and symptoms, lifestyle activities, avoidance of triggers and approaches to maintain overall health. The composite recommendations from HCPs and patients regarding an AP specific to COPD are summarized in Table 4. Key points include individualization of the AP, its presentation in a concise, legible format and regular reviews of its effectiveness.

We did not reach a consensus on the feasibility of patients using a daily diary as a component of their AP, although at least one clinical investigative group (13) has followed a cohort of COPD patients, with excellent responses to diary 
card completion over several years. Many HCPs indicated that it was unlikely that patients with COPD would complete daily diaries over an extended period of time, and patient responses varied across the spectrum. Clearly, self-efficacy and the patient's confidence that they are able to perform a particular task plays an important role in effecting behavioural change, and a negotiation process between HCPs and patients may be necessary in the construction of an $\operatorname{AP}(17,35,36)$.

There are no previous studies that reported on the patients' perspectives regarding an AP for COPD. In our study, one-half of the individuals with COPD thought that an AP would be beneficial to the care of their disease and one-third were unclear on this issue. In the study by Douglass et al (17), APs for asthma were considered useful by many patients. Even when patients did not have a formal AP, they frequently constructed their own AP. Of note, the AP was frequently (88\%) reinterpreted from the patient's perspective using their experience of the disease. This reinterpretation was considered a vital part of the implementation of an AP and supports the need for individualized plans.

Weaknesses of the present study include the difficulty of generalizing results from this relatively small sample to the much broader COPD population of patients with severe disease. The issue of appropriateness (ie, involving participants best positioned to provide useful information) was addressed by locating the study in an environment with access to clinically stable patients with severe chronic disease who had recently experienced AEs. The issue of adequacy (ie, having sufficient data to capture the broad range of experiences) was not problematic because we chose to report the frequency of responses and, therefore, content analysis did not require saturation to occur. Another difficulty was the absence of a general agreement on the definition of an exacerbation. Although the most widely accepted definition is that proposed by Anthonisen et al (24), pharmacotherapeutic trials have used other definitions based on worsening of symptoms that requires a change in the usual medications or in patterns of health care utilization, such as the number of hospitalizations (16).

Most interviews were individual because this format was more likely to encourage sequenced accounts of the patient's experiences and perceptions. We addressed what we considered to be two of the most important potential barriers to the use of an AP - an understanding of the patient's experience of an AE and the attitude of the HCPs to the use of an AP in COPD. We recognize that other barriers, such as health care system factors, were not explored in the present study. Poor comprehension, concentration or motivation may inhibit the patient's ability to recognize an AE, and unwillingness to take

\section{REFERENCES}

1. Troosters T, Casaburi R, Gosselink R, Decramer M. Pulmonary rehabilitation in chronic obstructive pulmonary disease. Am J Respir Crit Care Med 2005;172:19-38.

2. Von Korff M, Gruman J, Schaefer J, Curry SJ, Wagner EH. Collaborative management of chronic illness. Ann Intern Med 1997;127:1097-102.

3. Hiss RG, Anderson RM, Hess GE Stepien CJ, Davis WK. Community diabetes care. A 10-year perspective. Diabetes Care 1994;17:1124-34.

4. Rich MW, Beckham V, Wittenberg C, Leven CL, Freedland KE, Carney RM. A multidisciplinary intervention to prevent the readmission of elderly patients with congestive heart failure. N Engl J Med 1995;333:1190-5.

5. Beasley R, Cuchley M, Holgate ST. A self management plan in the treatment of adult asthma. Thorax 1989;44:200-4.

\author{
TABLE 4 \\ Recommendations of health care professionals and \\ patients regarding a chronic obstructive pulmonary \\ disease-specific action plan \\ - Targeted to the daily management of chronic obstructive pulmonary \\ disease and self-management of an acute exacerbation \\ - Includes symptoms of an acute exacerbation as defined by Anthonisen \\ (24) but also includes symptoms such as increased fatigue, mood \\ disturbances, chest tightness and difficulty sleeping, as well as other \\ individualized patient-specific symptoms \\ - Includes strategies useful to avoid exposure to individualized \\ environmental triggers, infective agents and any other patient-specific \\ triggers \\ - Provides a range of management options, such as an individualized \\ medication regimen, energy conservation and relaxation techniques, \\ breathing exercises and methods to relieve dyspnea \\ - Provides strategies to address mood disturbances \\ - Written in a clear, simple, concise format - no longer than one to two \\ pages in a large font \\ - Regularly reviewed to ensure its integration into daily life
}

control may prevent its use. HCPs who lack awareness of system cost-effectiveness, lack good educational material or lack a champion to promote a change from didactic teaching to selfmanagement can all be barriers to successful implementation of an AP (35).

Study strengths included the selection of experienced HCPs who were very familiar with chronic respiratory disease and had participated in many instances of exacerbation management. Another strength was the identification of repeated experiences rather than single or spectacular occurrences; thus, it was likely that we identified most of the broad range of patient symptoms that were likely to be associated with an exacerbation. Although this research was not designed to identify all the barriers to the use of an AP, nor to test a particular protocol, it does increase our understanding of the COPD patients' experience of an exacerbation, which is important for the development and testing of an $\mathrm{AP}$ as part of self-management education in COPD.

\section{CONCLUSIONS}

The observation that patients with COPD associate a variety of symptoms and signs with an AE emphasizes the importance of individualizing an AP to include the specific experiences of the patient. HCPs support the use of an AP and recommend that it address both exacerbations and general COPD management in a concise, legible manner.

6. Fishwick D, D'Souza W, Beasley R. The asthma self-management plan system of care: What does it mean, how is it done, does it work, what models are available, what do patients want and who needs it? Patient Educ Couns 1997;32(Suppl 1):S21-33.

7. Town GI, Hodges ID, Wilkie AT, Toop LJ, Graham P, Drennan CJ. A community-wide promotion of asthma self-management in New Zealand. Patient Educ Couns 1995;26:219-24.

8. Wolf FM, Guevara JP, Grum CM, Clark NM, Cates CJ. Educational interventions for asthma in children. Cochrane Database Syst Rev 2002:CD000326.

9. Bourbeau J, Julien M, Maltais F, et al; Chronic Obstructive Pulmonary Disease axis of the Respiratory Network Fonds de la Recherche en Sante du Quebec. Reduction of hospital utilization in patients with chronic obstructive pulmonary disease: A disease-specific selfmanagement intervention. Arch Intern Med 2003;163:585-91. 
10. Monninkhof EM, van der Valk PD, van der Palen J, et al. Self-management education for chronic obstructive pulmonary disease. Cochrane Database Syst Rev 2002:CD002990.

11. Monninkhof E, van der Valk P, van der Palen J, van Herwaarden C, Zielhuis $\mathrm{G}$. Effects of a comprehensive self-management programme in patients with chronic obstructive pulmonary disease. Eur Respir J 2003;22:815-20

12. Watson PB, Town GI, Holbrook N, Dwan C, Toop LJ, Drennan CJ. Evaluation of a self-management plan for chronic obstructive pulmonary disease. Eur Respir J 1997;10:1267-71.

13. Wilkinson TM, Donaldson GC, Hurst JR, Seemungal TA, Wedzicha JA. Early therapy improves outcomes of exacerbations of chronic obstructive pulmonary disease. Am J Respir Crit Care Med 2004;169:1298-303.

14. Seemungal TA, Donaldson GC, Bhowmik A, Jeffries DJ, Wedzicha JA. Time course and recovery of exacerbations in patients with chronic obstructive pulmonary disease. Am J Respir Crit Care Med 2000;161:1608-13.

15. O'Donnell DE, Aaron S, Bourbeau J, et al; Canadian Thoracic Society. Canadian Thoracic Society recommendations for management of chronic obstructive pulmonary disease -2003 . Can Respir J 2003;10(Suppl A):11A-65A.

16. Celli BR, Pinto-Plata V. Exacerbations in chronic lung disease and rehabilitation. In: Donner C, Ambrosino N, Goldstein R, eds. Pulmonary Rehabilitation. London: Hodder Arnold, 2005:362-8.

17. Douglass J, Aroni R, Goeman D, et al. A qualitative study of action plans for asthma. BMJ 2002;324:1003-5.

18. Berg BL. An introduction to content analysis. In: Qualitative Research Methods for the Social Sciences, 2nd edition. Boston: Allyn and Bacon, 1995:174-99.

19. The Asthma and Respiratory Foundation of New Zealand. Asthma self-management plan instructions. <http://www.asthmanz.co.nz/files/ PDF-files/manageplan.pdf $>$. (Version current at August 29, 2006).

20. The Symbicort "Take Control" card. Your asthma treatment plan. AstraZeneca.

21. Pauwels RA, Buist AS, Calverley PM, Jenkins CR, Hurd SS; GOLD Scientific Committee. Global strategy for the diagnosis, management, and prevention of chronic obstructive pulmonary disease. NHLBI/WHO Global Initiative for Chronic Obstructive Lung Disease (GOLD) Workshop summary. Am J Respir Crit Care Med 2001;163:1256-76

22. American Thoracic Society. Standards for the diagnosis and care of patients with chronic obstructive pulmonary disease. Am J Respir Crit Care Med 1995;152(Suppl 5):S77-121.

23. Seemungal TA, Donaldson GC, Paul EA, Bestall JC, Jeffries DJ, Wedzicha JA. Effect of exacerbation on quality of life in patients with chronic obstructive pulmonary disease. Am J Respir Crit Care Med 1998;157:1418-22.

24. Anthonisen NR, Manfreda J, Warren CP, Hershfield ES, Harding GK, Nelson NA. Antibiotic therapy in exacerbations of chronic obstructive pulmonary disease. Ann Intern Med 1987;106:196-204.

25. Gibson PG, Powell H, Coughlan J, et al. Self-management education and regular practitioner review for adults with asthma. Cochrane Database Syst Rev 2002:CD001117.

26. Gallefoss F, Bakke PS, Rsgaard PK. Quality of life assessment after patient education in a randomized controlled study on asthma and chronic obstructive pulmonary disease. Am J Respir Crit Care Med 1999; 159:812-7.

27. The National Lung Health Education Program (NLHEP). Strategies in preserving lung health and preventing COPD and associated diseases. Chest 1998;113(Suppl 2):123S-63.

28. National Collaborating Centre for Chronic Conditions. Chronic obstructive pulmonary disease. National clinical guideline on management of chronic obstructive pulmonary disease in adults in primary and secondary care. Thorax 2004;59(Suppl 1):1-232.

29. Donner CF, Muir JF. Selection criteria and programmes for pulmonary rehabilitation in COPD patients. Rehabilitation and Chronic Care Scientific Group of the European Respiratory Society. Eur Respir J 1997;10:744-57.

30. Kida K, Jinno S, Nomura K, Yamada K, Katsura H, Kudoh S. Pulmonary rehabilitation program survey in North America, Europe, and Tokyo. J Cardiopulm Rehabil 1998;18:301-8.

31. Carone M, Bertolotti G, Cerveri I, et al; Edu-Care Working Group. EDU-CARE, a randomised, multicentre, parallel group study on education and quality of life in COPD. Monaldi Arch Chest Dis 2002;57:25-9.

32. Carone M, Donner CF; EduCare Group. EduCare, an educational program for COPD, reduces exacerbations and improves quality of life. Am J Respir Crit Care Med 2003;167:A967. (Abst)

33. Parenteau S, Scott AS, McKnight J, Menzies D, Bourbeau J. Impact of an action plan that emphasizes the prompt use of oral prednisone and antibiotics in COPD exacerbation. Am J Respir Crit Care Med 2003;167:A230. (Abst)

34. Hodder R. The role of collaborative self-management education in pulmonary rehabilitation. In: Donner $\mathrm{C}$, Ambrosino $\mathrm{N}$, Goldstein R, eds. Pulmonary Rehabilitation. London: Hodder Arnold, 2005:205-18.

35. Jones A, Pill R, Adams S. Qualitative study of views of health professionals and patients on guided self management plans for asthma. BMJ 2000;321:1507-10.

36. Clark N, Gong M. Management of chronic disease by practitioners and patients: Are we teaching the wrong things? BMJ 2000;320:572-5. 


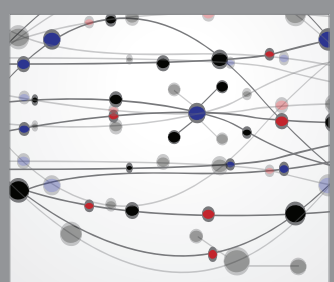

The Scientific World Journal
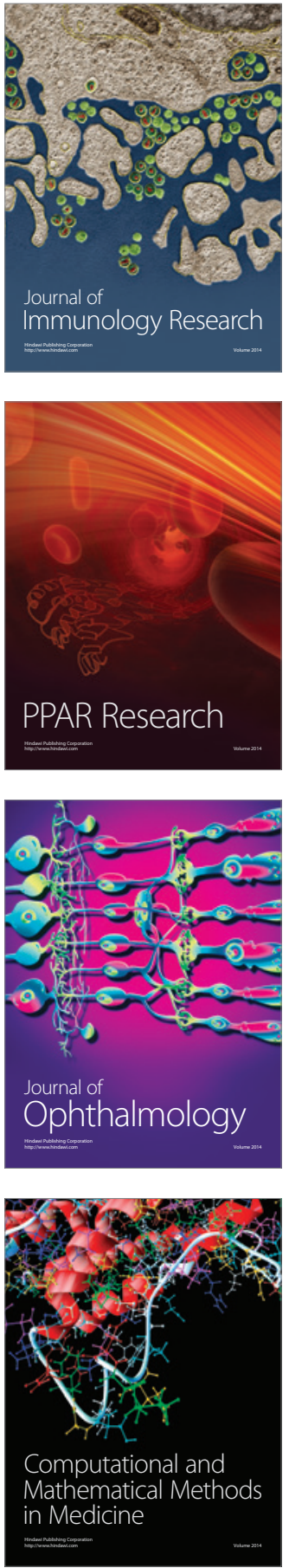

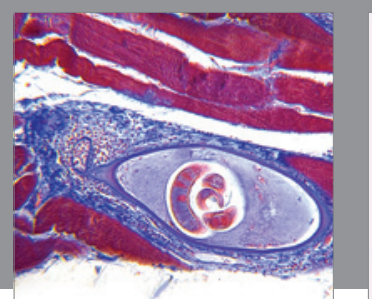

Gastroenterology Research and Practice

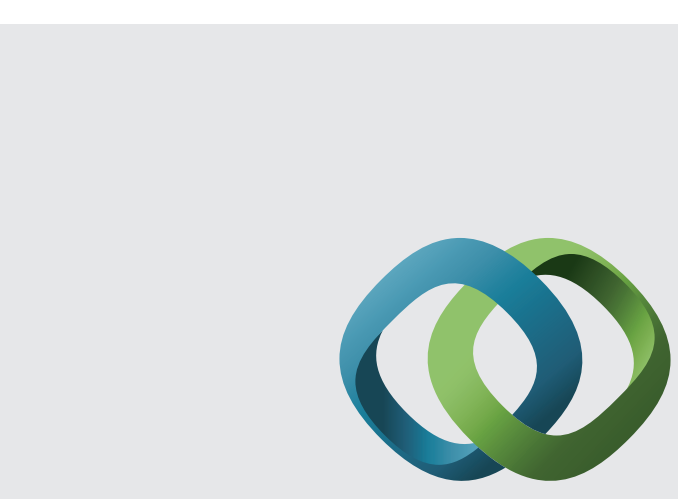

\section{Hindawi}

Submit your manuscripts at

http://www.hindawi.com
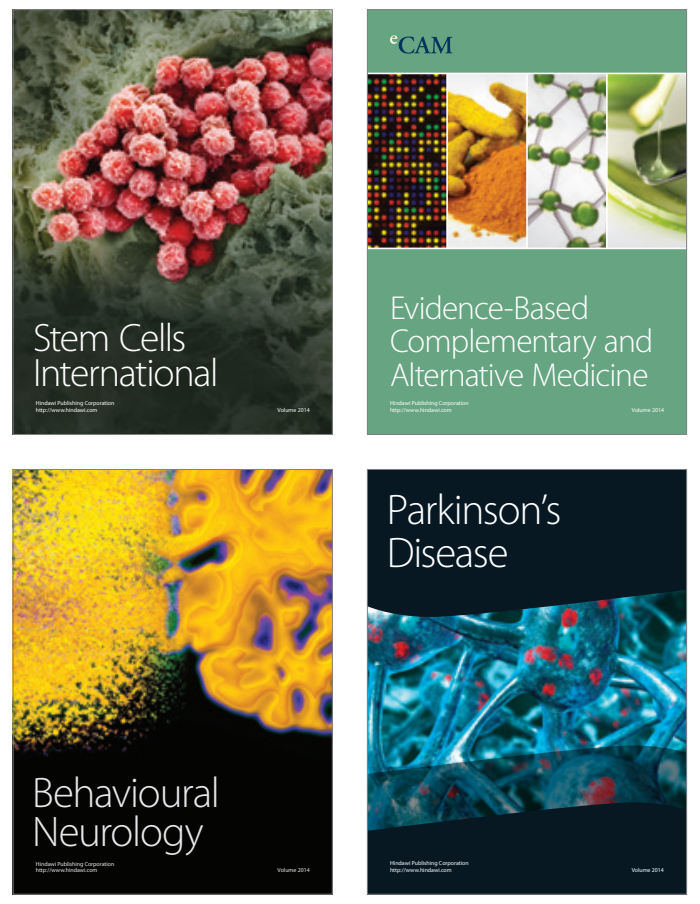
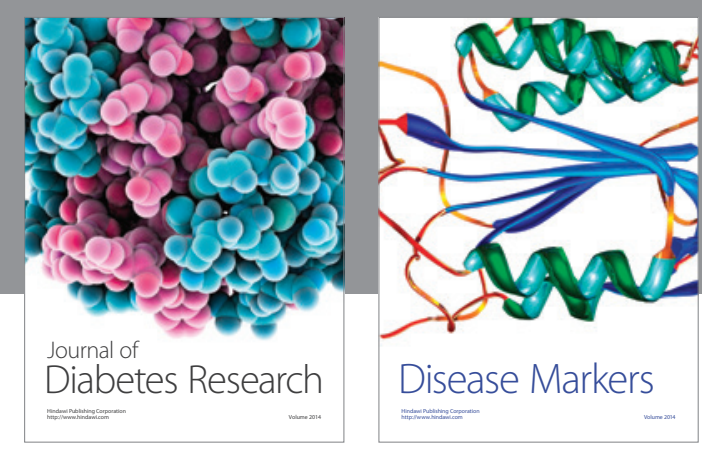

Disease Markers
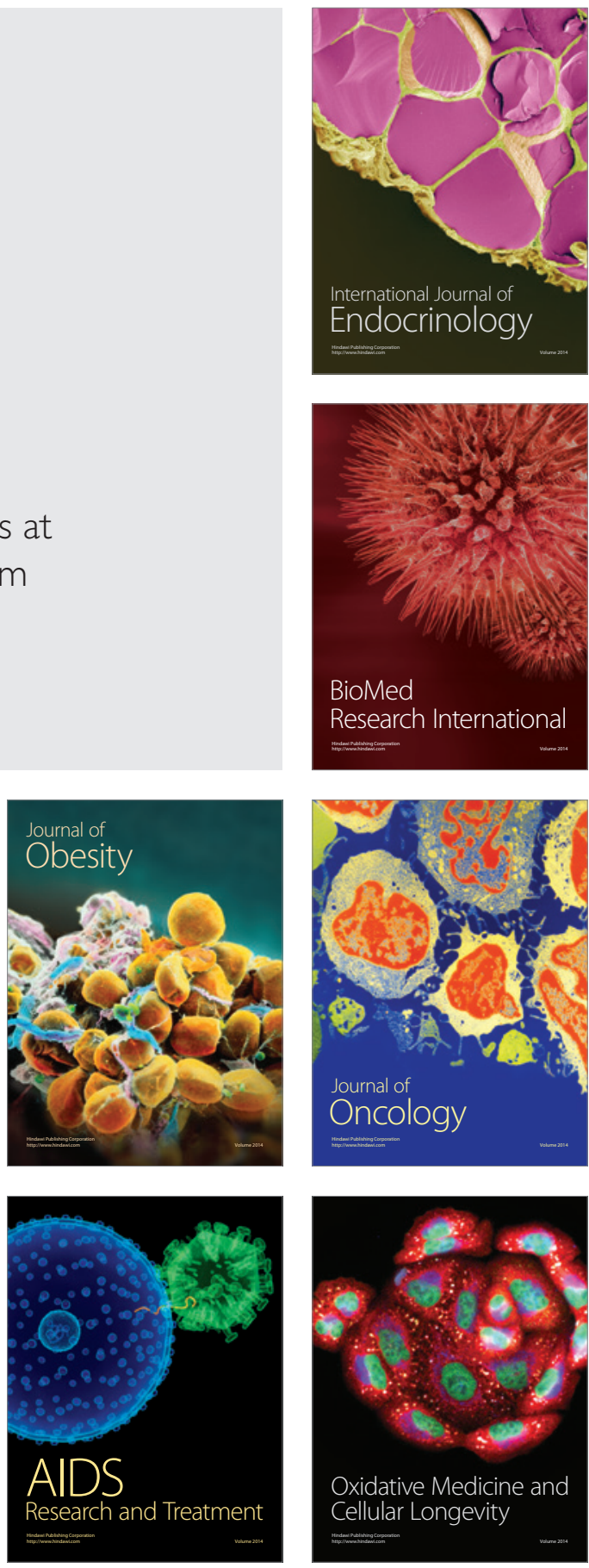